\title{
An alkaline route to prepare hydrothermally stable cubic Pm3n mesoporous silica using CTEA template
}

\author{
Ming-Chang Liu ${ }^{a}$, Chi-Shuang Chang ${ }^{a}$, Jerry C.C. Chan ${ }^{a}$, Hwo-Shuenn Sheu ${ }^{b}$, Soofin Cheng ${ }^{a, *}$ \\ a Department of Chemistry, National Taiwan University, No. 1, Roosevelt Rd., Sec. 4, Taipei 106, Taiwan \\ ${ }^{\mathrm{b}}$ Research Division, National Synchrotron Radiation Research Center, Hsinchu 300, Taiwan
}

\section{A R T I C L E I N F O}

\section{Article history:}

Received 28 October 2008

Received in revised form 1 January 2009

Accepted 6 January 2009

Available online 13 January 2009

\section{Keywords:}

Alkaline route

Cubic Pm3n

Mesoporous

SBA-1

CTEA

Pyrene fluorescence

Metal incorporation

Catalyst

\begin{abstract}
A B S T R A C T
Cubic Pm3n mesoporous silica isomorphous to SBA-1 with three-dimensional inter-connected pore structures was prepared for the first time in alkaline condition ( $\mathrm{pH}$ around 9 ) using sodium silicate as the silica source and cetyltriethylammonium $\left(\mathrm{CTEA}^{+}\right)$bromide as pore-directing agent with the aid of $\mathrm{NaCl} \mathrm{salt}$. In contrast to the conventional SBA-1 material prepared in the acidic environment, the mesostructure of the cubic Pm3n material, designated SBA-1-alk, was stable toward washing with water and hydrothermal treatment. The high stability is due to that the silicate condensation is more complete under the alkaline condition. The chemical forces governed the assembly of the surfactant and silicate in the alkaline condition was probed by pyrene fluorescence technique to be an $\mathrm{S}^{+} \mathrm{I}^{-}$type interaction. Moreover, the direct metal incorporation into the silica framework became very efficient through this alkaline route. The SBA1-alk isomorphously substituted with $\mathrm{Al}(\mathrm{III})$ was found an efficient catalyst for the alkylation of 2,4-ditert-butylphenol by cinnamyl alcohol to form flavan.
\end{abstract}

(c) 2009 Elsevier Inc. All rights reserved.

\section{Introduction}

Mesoporous molecular sieves [1-4] of high surface area and ordered uniform pores have been shown to be technologically promising for the applications in catalysis [5-7], sensors [8], optoelectronic devices [9], and biomedicine [10]. As the applications are concerned, three-dimensional inter-connected pore structures are usually favorable to the one-dimensional array of pores due to better pore accessibility. Cubic Pm $3 n$ phase SBA-1 silica with inter-connected network of cage-type pores was synthesized in strong acidic media $(\mathrm{pH} \ll 1)$ with surfactants of relatively large head group $\left(\mathrm{C}_{n} \mathrm{H}_{2 n+1}\left(\mathrm{C}_{2} \mathrm{H}_{5}\right)_{3} \mathrm{~N}^{+}, n=12,14,16\right.$, and 18 ), which tend to form globular micelles [2-4,11]. The drawback of the material from practical applications has been the low stability of the as-made samples toward washing with water [12]. Moreover, phase transformation of the materials upon drying was observed $[13,14]$. Efforts have been made to overcome this disadvantage by increasing the amount and concentration of acid used [15] or concomitantly adding auxiliary agents [16]. On the other hand, the incorporation of metal ions into the framework of mesoporous silica is important in order to introduce functionalities and broaden its applications [17-20]. However, under the strongly acidic synthesis condition, metal incorporation into SBA-1 has

\footnotetext{
* Corresponding author. Tel.: +886 2 23638017; fax: +886 223636359

E-mail address: chem1031@ntu.edu.tw (S. Cheng).
}

been very inefficient [18-20]. The metal loadings are usually very low, and the metal ions often form extra-framework species instead of isomorphous substitution for the silicon sites [17].

A model involving "charge density matching" has been proposed to explain the self-assembly of surfactant and silica precursor during the mesophases formation [3]. Under acidic condition with $\mathrm{pH}$ below the isoelectric point of silanol ( $\mathrm{pH} \sim 2$ ), the protonated silanol groups $\left(\mathrm{I}^{+}\right)$react with positive charged surfactants $\left(\mathrm{S}^{+}\right)$via the counteranions $\left(\mathrm{X}^{-}\right)$through a $\mathrm{S}^{+} \mathrm{X}^{-} \mathrm{I}^{+}$type interaction. In contrast, in aqueous solution of $\mathrm{pH}$ higher than 2 , the selfassembly is considered through a stronger $\mathrm{S}^{+} \mathrm{I}^{-}$type interaction, where $\mathrm{I}^{-}$stands for $\mathrm{Si}-\mathrm{O}^{-}$groups. Conventionally, SBA- 1 is prepared in strongly acidic media. Huo et al. [11] has attributed the difficulties of forming silica mesophases with a globular micellar aggregate in basic medium to that the surface of globular micelle has the largest surface curvature and the lowest charge density of all lyotropic liquid crystals. It is difficult to have charge matching for the silicate framework in the $\mathrm{Si}-\mathrm{O}^{-}$form of high charge density under alkaline condition with that of the globular micelle. Up to now, only three papers have reported the preparation of cubic Pm3n mesoporous silica materials at $\mathrm{pH}$ values close to or higher than the isoelectric point of silanol. Chao et al. [21] have slowly grown SBA-1 silica of cube-shape morphology in an extremely diluted cetyltrimethylammonium (CTMA) solution at $\mathrm{pH} 1-2$. The $\mathrm{pH}$ value for preparing cubic $\mathrm{Pm} 3 n$ mesoporous silica was raised to 4-7 when a stoichiometric amount of poly(acrylic 
acid) was mixed with $\mathrm{C}_{14}$ TMA pore-directing agent to stabilize the spherical micelles [22]. On the other hand, SBA-6 which is also a cubic $P m 3 n$ mesoporous silica was prepared by using a gemini surfactant, $18 \mathrm{~B}_{4-3-1} \quad\left(N, N, N, N^{\prime}, N^{\prime}\right.$-pentamethyl- $N^{\prime}$-[4-(4octadecyloxyphenoxy)-butyl]-propane-1,3-diammonium dibromide), and benzyltrimethylammonium hydroxide as the base to hydrolyze TEOS [23]. In the present study, well-ordered cubic Pm3n silica was prepared for the first time using sodium silicate as the silica source and $\mathrm{CTEA}^{+}$(cetyltriethylammonium) bromide as the poredirecting agent with the optimal $\mathrm{pH}$ value of the synthesis solution around 9 . In contrast to the conventional synthesis condition of SBA-1, where large amount of mineral acid is needed and tetraethylorthosilicate (TEOS) was the silica source, the alkaline route is more economical and environmentally friendly. Most of all, hetero-elements could be efficiently incorporated into the silica framework through isomorphous substitution, and the cubic mesostructure of the resultant materials was stable toward washing with water and hydrothermal treatment. The catalytic properties of the aluminum-incorporated cubic Pm $3 n$ mesoporous silica were examined by carrying out the alkylation of 2,4-di-tert-butylphenol with cinnamyl alcohol as a model reaction [24,25].

\section{Experimental}

\subsection{Preparation of cubic Pm3n mesoporous silica in alkaline condition}

In the typical procedure, the pore-directing agent CTEABr was first dissolved in an aqueous solution containing sodium chloride and a small amount of hydrochloric acid. To this mixture at desired temperature, the aqueous solution of sodium silicate was added so that the $\mathrm{pH}$ value of the final solution was in 3-11. The molar composition of the reaction mixture was $\mathrm{Na}_{2} \mathrm{SiO}_{3} / \mathrm{CTEABr} / \mathrm{NaCl} / \mathrm{HCl} /$ $\mathrm{H}_{2} \mathrm{O}=1.0 / 0.26 / 0-10 / 0.56-0.83 / 500$, where the acid content was much lower than that in conventional synthesis route $(\mathrm{HCl} /$ TEOS 3-140). The mixture was stirred for $10 \mathrm{~min}$ and then aged for $48 \mathrm{~h}$. The solid product was recovered by filtration, washing thoroughly with distilled water, and drying at $100{ }^{\circ} \mathrm{C}$ overnight. To remove the template, the as-synthesized samples were calcined in air under static condition at $550^{\circ} \mathrm{C}$ for $6 \mathrm{~h}$. The resultant materials are designated "SBA-1-alk".

\subsection{Preparation of Al(III)-incorporated cubic Pm3n mesoporous silica under alkaline condition}

CTEABr was first dissolved in an aqueous solution containing sodium chloride and a small amount of hydrochloric acid. To this mixture at $0{ }^{\circ} \mathrm{C}$, the aqueous solution containing sodium aluminate and sodium silicate with $\mathrm{Al} / \mathrm{Si}$ atomic ratios varied in $1-7 \%$ was added so that the $\mathrm{pH}$ value of the final solution was kept around 9. The molar composition of the reaction mixture was $\mathrm{Na}_{2} \mathrm{SiO}_{3} /$ $\mathrm{NaAlO}_{2} / \mathrm{CTEABr} / \mathrm{NaCl} / \mathrm{HCl} / \mathrm{H}_{2} \mathrm{O}=1.0 / 0.01-0.07 / 0.26 / 6 / 0.60 / 500$.

After stirring for $10 \mathrm{~min}$, the mixture was aged at $0{ }^{\circ} \mathrm{C}$ for $48 \mathrm{~h}$. The solid product was recovered by filtration, washing thoroughly with distilled water, and drying at $100{ }^{\circ} \mathrm{C}$ overnight. To remove the template, the as-synthesized samples were calcined in air under static condition at $550{ }^{\circ} \mathrm{C}$ for $6 \mathrm{~h}$. The resultant materials are named "AlSBA-1-alk".

\subsection{Pyrene fluorescence}

In the pyrene fluorescence experiments, trace amount of pyrene $(3 \mu \mathrm{M})$ was dissolved in the CTEA ${ }^{+}$micelles $(0.058 \mathrm{M})$ before the introduction of silica source. An appropriate amount of the stock solution of pyrene $(12 \mathrm{mM})$ in ethanol was introduced into a volumetric flask and spread over the flask wall. Then ethanol was evap- orated away by a gentle stream of nitrogen. A $0.058 \mathrm{M}$ CTEABr solution was introduced into the volumetric flask containing pyrene, and the mixture was stirred at $30^{\circ} \mathrm{C}$ for at least $12 \mathrm{~h}$ to reach equilibrium. The other procedure for preparing mesoporous silica was the same as that for synthesis of cubic Pm $3 n$ mesoporous silica mentioned above.

\subsection{Hydrothermal stability}

To examine the hydrothermal stability of the synthesized materials, about $0.5 \mathrm{~g}$ of the calcined sample was dispersed in $50 \mathrm{~mL}$ of de-ionized water. The mixture was sealed in a polypropylene (PP) bottle and heated at $100{ }^{\circ} \mathrm{C}$ under static condition for 5 days. The solid was then filtered and dried at $100{ }^{\circ} \mathrm{C}$ overnight.

\subsection{Catalytic reaction procedure}

To generate Brønsted acid sites on Al-SBA-1-alk, the calcined samples were ion-exchanged with $1 \mathrm{M} \mathrm{NH}_{4} \mathrm{Cl}$ solution twice, followed by filtration, washing with de-ionized water, drying at $100{ }^{\circ} \mathrm{C}$, and calcination at $550^{\circ} \mathrm{C}$ again. Before used as the catalyst, the solid was baked at $200{ }^{\circ} \mathrm{C}$ at least for $5 \mathrm{~h}$ to remove adsorbed moisture. The alkylation of 2,4-di-tert-butylphenol (2,4-DTBP) with cinnamyl alcohol was performed in a $50 \mathrm{~mL}$ flask immersed in a thermostat bath with a magnetic stirrer. About $100 \mathrm{mg}$ of the catalyst suspended in $12.5 \mathrm{~mL}$ dimethyl sulfoxide (DMSO) was mixed with $0.25 \mathrm{mmol}$ of 2,4-di-tert-butylphenol (Aldrich) and $0.20 \mathrm{mmol}$ of cinnamyl alcohol (Aldrich), and the reaction was proceeded at $95^{\circ} \mathrm{C}$ for $24 \mathrm{~h}$. After quenching to room temperature, the liquid products were separated from the solid catalyst by filtration and analyzed with a Chrompack 9000 gas chromatograph equipped with a flame ionization detector and a RTX-5 capillary column ( $30 \mathrm{~m} \times 0.53 \mathrm{~mm}$ ) using toluene as an internal standard.

\subsection{Characterization}

Powder XRD patterns were recorded using a PANalytical X'pert Pro diffractometer with $\mathrm{Cu} \mathrm{K} \alpha$ radiation operated at $40 \mathrm{~mA}$ and $45 \mathrm{kV}$. In situ XRD studies were conducted at beam-line 17A of the NSRRC, Hsinchu, Taiwan. The patterns were recorded in the transmission mode (1.5 GeV and $120-200 \mathrm{~mA}$ ). The wavelength of synchrotron radiation at $17 \mathrm{~A}$ is $0.131-0.133 \mathrm{~nm}$. The in situ XRD data were expressed in scattering vector $q$, where $q=4 \pi \sin \theta / \lambda=2 \pi / d . \mathrm{N}_{2}$ sorption isotherms were measured using a Micromeritics Tristar 3000 system at liquid nitrogen temperature $(77 \mathrm{~K})$. Before the measurements, the samples were degassed at $200{ }^{\circ} \mathrm{C}$ for $10 \mathrm{~h}$ under vacuum $\left(10^{-3} \mathrm{Torr}\right)$. The surface areas were evaluated using Brunauer-Emmett-Teller (BET) method. Pore size distribution was determined by Barrett-Joyner-Halenda (BJH) method using the desorption branch of the isotherms and the pore sizes were obtained from the peak positions of the distribution profiles. Transmission electron microscopy (TEM) was performed on a Hitachi H-7100 electron microscope, operating at $75 \mathrm{kV}$, and SEM images were taken using a Hitachi S-800 field emission scanning electron microscope. The energy dispersed X-ray (EDX) emission spectra were taken with a Hitachi S-2400 scanning electron microscope. The ${ }^{29} \mathrm{Si}$ and ${ }^{27} \mathrm{Al} \mathrm{NMR}$ experiments were carried out at frequencies of 59.63 and $78.21 \mathrm{MHz}$, respectively, on a Brucker MSL-300 NMR spectrometer equipped with a commercial $7 \mathrm{~mm}$ MAS NMR probe. The magic-angle spinning frequencies were set to $5 \mathrm{kHz}$ for all experiments. Chemical shifts were externally referenced to $\mathrm{Si}\left(\mathrm{CH}_{3}\right)_{4}$ and $1 \mathrm{M} \mathrm{Al}\left(\mathrm{NO}_{3}\right)_{3}$ solution. The $Q^{4} /\left(Q^{2}+Q^{3}\right)$ area ratios were obtained by deconvolution of the peaks in the spectra using WinFit software. The inductively coupled plasma-atomic emission spectra (ICP-AES) of the samples dissolved in mixed HF$\mathrm{HNO}_{3}$ solutions were taken using an ELAN 5000 instrument. 
Steady-state fluorescence measurements were performed using an EDINBURGH FS900 fluorescence spectrometer. Pyrene was excited with a $338 \mathrm{~nm}$ light source and the emission wavelength was collected in the range of 350-600 nm. The fluorescence lifetimes were measured by time-correlated single-photon counting apparatus. Samples were excited with $338 \mathrm{~nm}$ light source and the detection was made at $395 \mathrm{~nm}$. The fluorescence decay profiles were analyzed with a nonlinear least-squares iterative reconvolution method. For solution samples, the fluorescence quartz cell ( $1 \mathrm{~cm}$ in thickness) was used. To measure the spectra of the solid samples, the gel after $24 \mathrm{~h}$ crystallization period was wiped on a quartz plate as a film of ca. $1 \mathrm{~mm}$ thickness. The size of the quartz plate was $1.5 \mathrm{~mm} \times 1.4 \mathrm{~cm} \times 4.5 \mathrm{~cm}$. The quartz plate was then inserted into the diagonal of the quartz cell to minimize the light scattering.

\section{Results and discussion}

\section{1. $\mathrm{NaCl}$ effect in alkaline condition}

Fig. 1 shows the small angle XRD patterns of the as-made and calcined materials prepared at $\mathrm{pH} 9$ with various amounts of $\mathrm{NaCl}$. The solid products synthesized without $\mathrm{NaCl}$ showed only poorly resolved XRD bands in the small angle region, while the ordering of the pore structure was significantly improved by adding a proper amount of $\mathrm{NaCl}$ salt ( $\mathrm{NaCl} / \mathrm{Si}$ molar ratio in 6-10) into the synthesis mixture. The XRD patterns of the calcined samples not only show three distinct diffraction peaks at $2 \theta \sim 1.5-2.5^{\circ}$ indexed to the (200), (210), and (211) planes of cubic Pm3n symmetry, but also four weaker peaks at $2 \theta \sim 2.5-4^{\circ}$ assignable to the $(222)$, (320), (321), and (400) planes.

The solid state ${ }^{29} \mathrm{Si}$ MAS NMR spectra of the as-made samples were also shown in Fig. 1. Two distinct resonance peaks at -98 and $-107 \mathrm{ppm}$ corresponding to $Q^{3}$ and $Q^{4}$, respectively, as well as a weak shoulder at $-88 \mathrm{ppm}$ for $Q^{2}$ were clearly seen, where $Q^{n}$ represents $\mathrm{Si}$ in different coordination environments of $\mathrm{Si}(\mathrm{OSi})_{n}(\mathrm{OH})_{4-n}$ and $n=2-4$. The relative integrated intensities of the $Q^{4} /\left(Q^{2}+Q^{3}\right)$ signals for the samples synthesized with $\mathrm{NaCl}$ are higher than that without $\mathrm{NaCl}(1.32-1.34$ vs. 1.01$)$, implying that the presence of $\mathrm{NaCl}$ could enhance silicate condensation.
The degree of silicate condensation and the ordering of the mesostructure were not further improved when the $\mathrm{NaCl} / \mathrm{Si}$ molar ratios were greater than 6 . Therefore, the materials studied hereafter were prepared with a $\mathrm{NaCl} / \mathrm{Si}$ molar ratio of 6 .

The thermal stability of cubic Pm $3 n$ mesoporous silica prepared at $\mathrm{pH} 9$ with various amounts of $\mathrm{NaCl}$ was examined by thermogravimetric analysis (TGA). Fig. 2 shows that all the as-made samples lost weight in two steps: about $3-5 \%$ at $30-110{ }^{\circ} \mathrm{C}$ is due to the desorption of water, and another $38-50 \%$ at $150-400{ }^{\circ} \mathrm{C}$, is attributed to the combustion and decomposition of the $\mathrm{CTEA}^{+}$template. However, the differential (DTA) peak shifts toward higher temperature, and the amount of template incorporated increases with the increase in the amount of $\mathrm{NaCl}$ added, implying that the interaction between the template and silica wall is enhanced by the presence of $\mathrm{NaCl}$.

The elemental analysis by EDX showed that $\mathrm{NaCl}$ can be thoroughly removed by washing with water. For instance, the $\mathrm{Si} / \mathrm{Na} /$ $\mathrm{Cl}$ molar ratio in the as-made SBA-1-alk sample was 1.0:0.29:0.31, while that of washed sample was 1.0:0.00:0.01. These results infer that sodium and chloride ions are not incorporated into the silica mesostructure. These results are in consistence with the "charge density matching" model. Under alkaline condition, the silicate $\left(\mathrm{I}^{-}\right)$and cationic micelle $\left(\mathrm{S}^{+}\right)$are considered to assemble through an $\mathrm{S}^{+} \mathrm{I}^{-}$-type interaction and no counteranions $\left(\mathrm{X}^{-}\right)$are needed during the self-assembly process [3]. Moreover, the cubic SBA-1-alk prepared in alkaline condition overcomes the drawback of the conventional SBA-1 prepared in acid, whose asmade material has low stability toward washing with water [12]. That is probably attributed to the strong $\mathrm{S}^{+} \mathrm{I}^{-}$-type interaction as well as the high degree of silicate condensation of the silica walls of the cubic mesoporous silica prepared in alkaline condition.

It has been suggested that salts can decrease the critical micelle temperature (CMT) of the surfactants and increase the ionic strength of synthesis solutions, and thus facilitate the self-assembly of the micelles and inorganic precursors [26-29]. On the other hand, the anions like chloride, were considered to render the hydrophobic part of the surfactant by so-called salting-out effect, and stabilize the micelle structure [30-33]. The present study further demonstrates that $\mathrm{NaCl}$ salt can enhance silicate condensation, which has been previously reported by our laboratory [34].
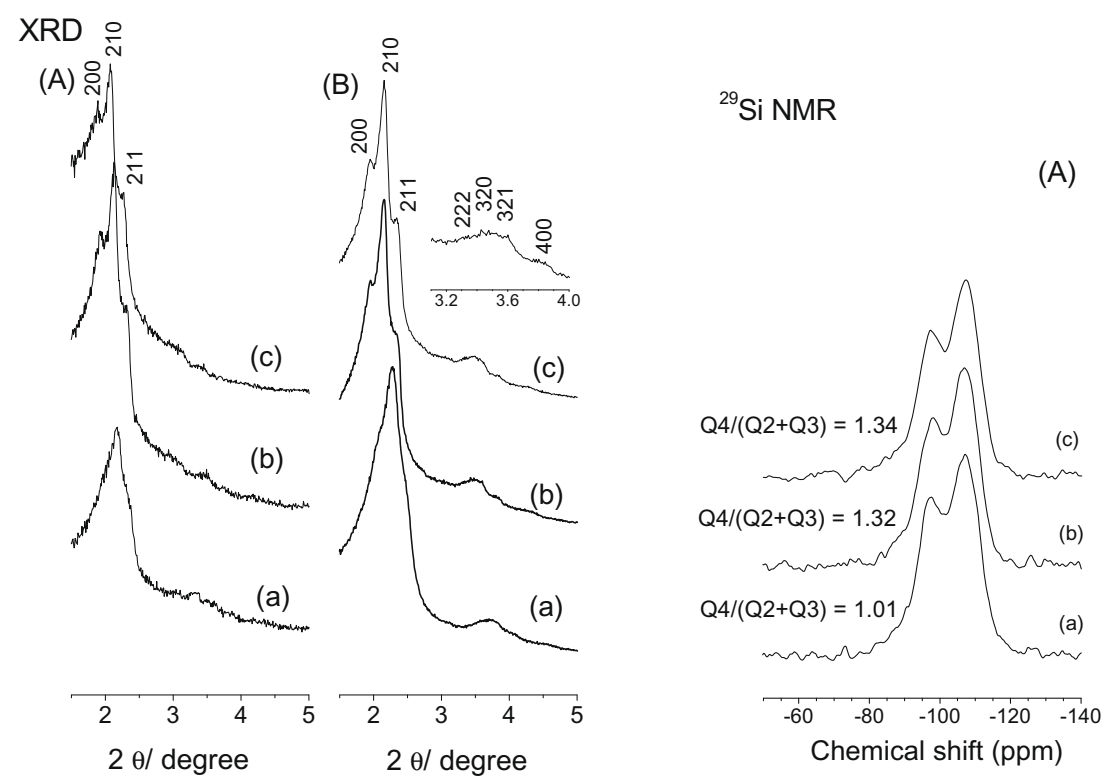

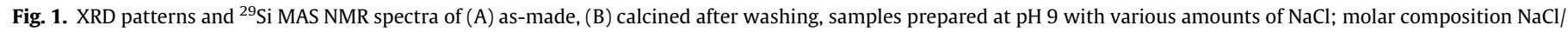
$\mathrm{Na}_{2} \mathrm{SiO}_{3}=$ (a) 0 , (b) 6, and (c) 10 . 
A

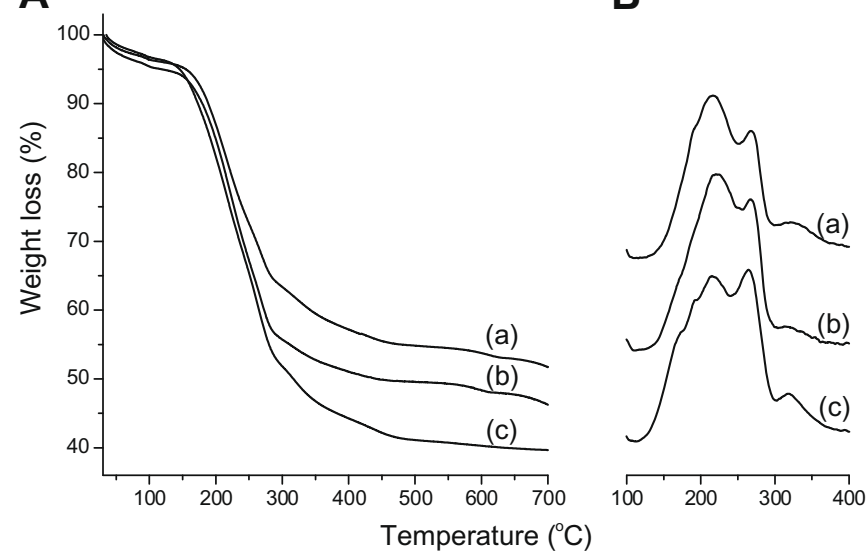

Fig. 2. (A) TGA and (B) DTG profiles taken in air atmosphere of as-synthesized mesostructured silica prepared at pH 9 with $\mathrm{NaCl} / \mathrm{Si}$ of (a) 0, (b) 6, and (c) 10 .

\section{2. $p H$ effect}

The effect of pH value of the synthesis solution on the mesostructure was examined by X-ray diffraction and ${ }^{29} \mathrm{Si}$ MAS NMR and the results are shown in Fig. 3. The as-made samples prepared in the $\mathrm{pH}$ range of 3-11 all possessed XRD patterns of cubic Pm3n phase. It is for the first time to report that cubic Pm3n mesoporous silica can be synthesized in such a wide range of $\mathrm{pH}$ values. After they were thoroughly washed with water and then calcined at $550{ }^{\circ} \mathrm{C}$ for $6 \mathrm{~h}$, only the samples prepared at $\mathrm{pH} \mathrm{8-10}$ retained well-resolved XRD peaks. It is attributed to that the silica condensation is probably more complete under alkaline condition. ${ }^{29} \mathrm{Si}$ MAS NMR spectra of the as-made samples show that the integrated intensity ratio of the $Q^{4} /\left(Q^{2}+Q^{3}\right)$ signals for the sample prepared at pH 9 is significantly higher than that at pH 6 (1.32 vs. 0.96$)$, confirming that higher degree of silicate condensation was achieved
A

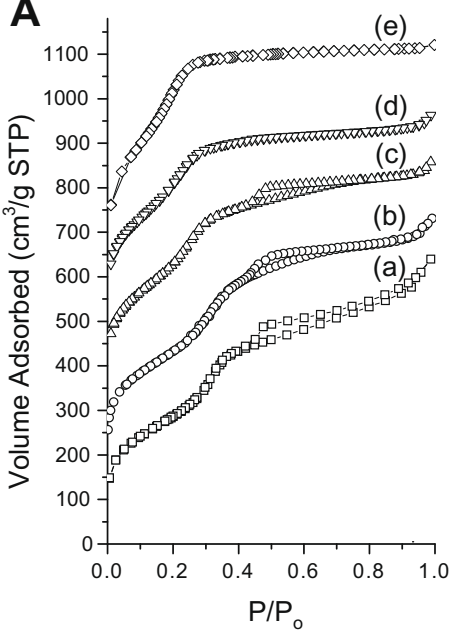

B

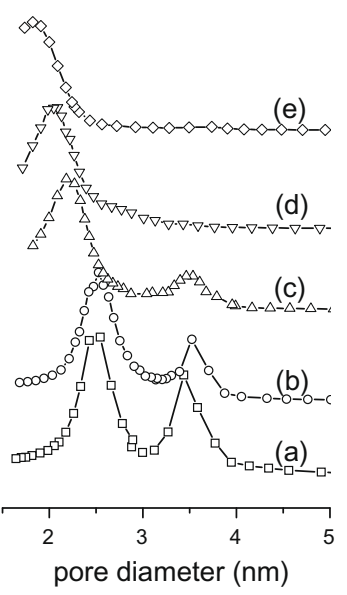

Fig. 4. (A) $\mathrm{N}_{2}$ adsorption/desorption isotherms (shifted in vertical axis by 0,150 , 300,450 and $600 \mathrm{~cm}^{3} / \mathrm{g}$ STP, respectively), and (B) BJH pore size distribution of calcined samples synthesized at $\mathrm{pH}$ (a) 10 , (b) 9 , (c) 8 , (d) 7 , and (e) -0.3 .

at higher $\mathrm{pH}$ value. However, solubility of silica becomes pronounced if the $\mathrm{pH}$ of the solution is larger than 10 .

The textural properties of the calcined SBA-1-alk samples were examined by $\mathrm{N}_{2}$ physisorption experiments, and the results are shown in Fig. 4 and Table 1. The calcined SBA-1-alk samples have type IV isotherms according to the IUPAC classification, and that was the characteristics of ordered mesoporous materials. They are basically in the shape similar to that of cubic SBA-1 [2-4]. However, the pore size distribution is not as broad as that of conventional SBA-1 synthesized in acid. The surface areas were 1008 , 1328,1432 , and $1022 \mathrm{~m}^{2} / \mathrm{g}$ and the pore volumes were 0.81 , $0.89,1.03$, and $0.94 \mathrm{~cm}^{3} / \mathrm{g}$ for the samples synthesized at $\mathrm{pH}$ values of $7,8,9$, and 10 , respectively. Moreover, the $\mathrm{BJH}$ pore diameter in-

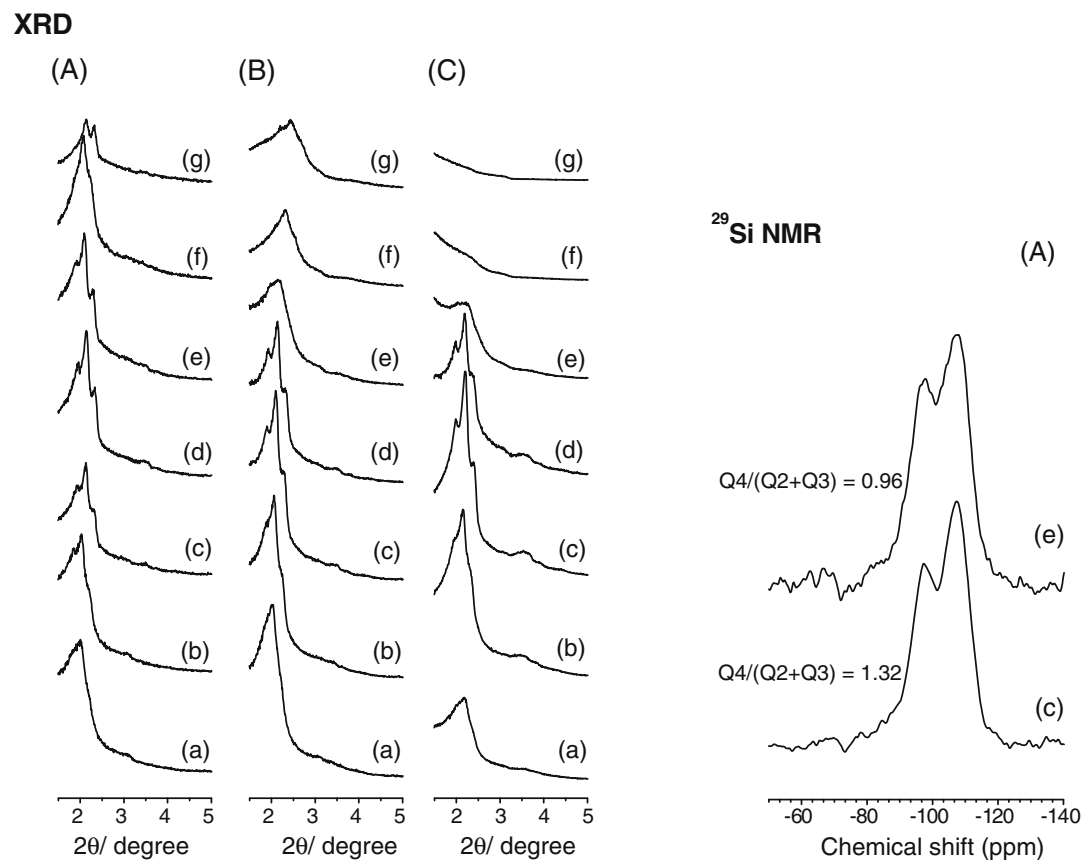

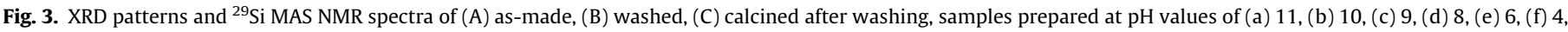
and (g) 3; molar composition $\mathrm{Na}_{2} \mathrm{SiO}_{3} / \mathrm{CTEABr} / \mathrm{NaCl} / \mathrm{HCl} / \mathrm{H}_{2} \mathrm{O}=1.0 / 0.26 / 6.0 / 0.56-0.83 / 500$. 
Table 1

Structural parameters of calcined cubic Pm $3 n$ mesoporous silica samples prepared at different values of $\mathrm{pH}$ by $\mathrm{N}_{2}$ adsorption/desorption experiments.

\begin{tabular}{clllll}
\hline $\mathrm{pH}$ & $a_{0}(\mathrm{~nm})$ & & $S_{\text {BET }}\left(\mathrm{m}^{2} / \mathrm{g}\right)$ & $D_{\text {meso }}(\mathrm{nm})$ & $V_{\text {pore }}\left(\mathrm{cm}^{3} / \mathrm{g}\right)$ \\
\cline { 2 - 4 } & As-made & Calcined & & & \\
\hline$-0.3^{*}$ & 9.58 & 8.63 & 1430 & 1.8 & 0.93 \\
7 & 9.30 & 8.91 & 1008 & 2.0 & 0.81 \\
8 & 9.30 & 9.04 & 1328 & $2.2,3.5$ & 0.89 \\
9 & 9.39 & 9.06 & 1432 & $2.5,3.5$ & 1.03 \\
10 & 9.48 & 9.09 & 1022 & $2.5,3.4$ & 0.94 \\
\hline
\end{tabular}

$\mathrm{pH}-0.3$ is calculated for $[\mathrm{HCl}]=2.2 \mathrm{M}\left(\mathrm{pH}=-\log \left[\mathrm{H}^{+}\right]\right)$. The acidic synthesis condition was TEOS $/ \mathrm{CTEABr} / \mathrm{HCl} / \mathrm{H}_{2} \mathrm{O}=1.0: 0.13: 5.0: 125$ at $0{ }^{\circ} \mathrm{C}$ for 1 day.

creases with the $\mathrm{pH}$ value of the synthesis solution up to a $\mathrm{pH}$ value of 9. In general, the samples prepared in alkaline conditions have larger pore diameters than that prepared in acid. However, these samples also tend to contain a small amount of larger pores of ca. $3.5 \mathrm{~nm}$ in diameter other than the mesopores in $2.2-2.5 \mathrm{~nm}$. Since the hysteresis loop increases in area as $\mathrm{pH}$ raises, those pores of ca. $3.5 \mathrm{~nm}$ are likely due to the structural defects formed during the rapid precipitation. Although the amount of defects increases with $\mathrm{pH}$ value of the synthesis solution, the SBA-1-alk samples prepared at $\mathrm{pH}$ 8-10 can well retain the cubic mesoporous structure after being washed with water and calcined at $550{ }^{\circ} \mathrm{C}$. Moreover, the calcined sample prepared at $\mathrm{pH} 9$ has the largest surface area and pore volume. Therefore, $\mathrm{pH} 9$ is the optimal synthesis condition used hereafter.

SEM images show that the cubic mesoporous materials synthesized by alkaline route were generally spherical without any facets (Fig. 5). The particle size of the spheres was $\mathrm{pH}$ dependent, due to that the rates of silicate hydrolysis and condensation are strongly influenced by the $\mathrm{pH}$ of the synthesis solution. For the material synthesized at $\mathrm{pH} 9$, the particles were very small of around $100-300 \mathrm{~nm}$ in diameter. On the other hand, the particles of SBA-1 synthesized by acidic route have well-defined external morphology with crystal facets, and the particle size was usually in 3$15 \mu \mathrm{m}[35]$.

TEM photographs confirm that the materials synthesized by alkaline route possessed long-range ordering of the three-dimensional cubic arrays. The average pore diameter determined from TEM photographs is $2.4 \mathrm{~nm}$, which is in consistence with that from $\mathrm{N}_{2}$ sorption experiments.

\subsection{Effect of sodium silicate concentration}

The concentration of sodium silicate in the synthesis solutions was found to have pronounced effects on the textural properties of the resulting cubic Pm $3 n$ mesoporous silica. When doubling the silicate concentration but keeping those of other components the same and final $\mathrm{pH}$ of 8-9 (molar composition in $\mathrm{Na}_{2} \mathrm{SiO}_{3} / \mathrm{CTEABr} /$ $\left.\mathrm{NaCl} / \mathrm{HCl} / \mathrm{H}_{2} \mathrm{O}=1.0 / 0.13 / 3.0 / 0.59-0.63 / 250\right)$, the resultant materials are still well-ordered cubic Pm3n phase (Fig. 6A). After calcination, the intensity of X-ray diffraction peaks of the sample synthesized with diluted silicate increases markedly due to the raise in background contrast, while those of samples prepared with concentrated silicate are much weaker. Moreover, the diffraction peaks of the latter samples shift ca. $0.2^{\circ}$ towards lower angles, inferring the shrinkage of unit cell upon calcination, which was not seen on the sample prepared with diluted silicate. These results imply that the materials prepared with concentrated silicate solutions are less stable. The $\mathrm{N}_{2}$ physisorption isotherms of calcined samples are shown in Fig. 6B. The calcined cubic Pm $3 n$ mesoporous silica synthesized with concentrated silicate concentration still have type
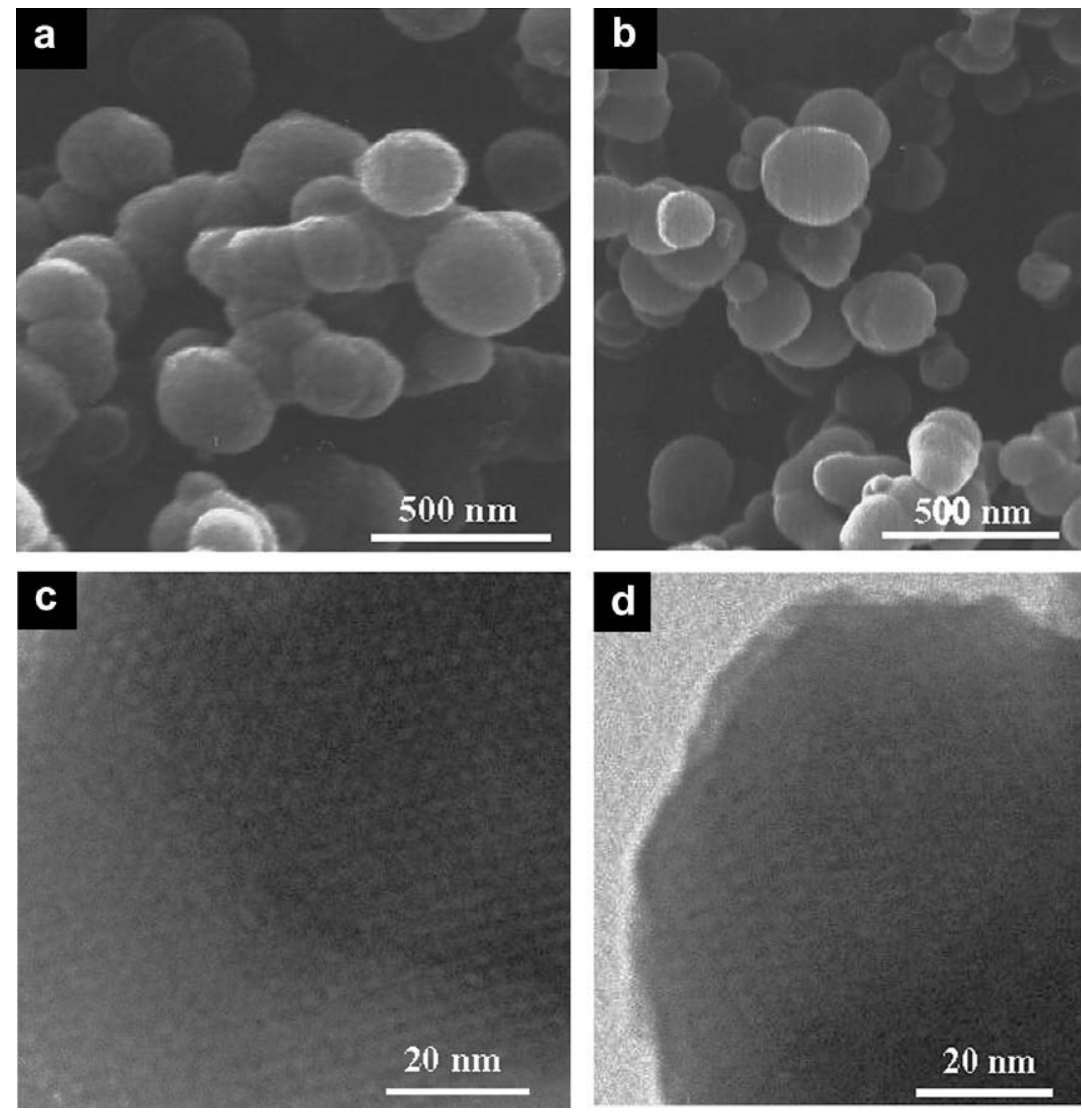

Fig. 5. SEM and TEM photographs of calcined SBA-1-alk samples synthesized at pH (a and c) 8.0 and (b and d) 9.0 
IV isotherms but the hysteresis loops in $P / P_{0}>0.4$ region are different from that synthesized with diluted silicate. The moving of the hysteresis loops to $P / P_{0} \sim 0.6-1$ and abrupt increases in volume of $\mathrm{N}_{2}$ absorption near saturated vapor pressure imply that the materials are aggregates of nanoparticles, which are confirmed by the SEM photographs shown in Fig. 6C. The surface areas and pore volumes of the samples synthesized with concentrated silicate at $\mathrm{pH}$ 8-9 are $1053-1060 \mathrm{~m}^{2} / \mathrm{g}$ and $0.84-0.90 \mathrm{~cm}^{3} / \mathrm{g}$, respectively, and all are smaller than those of the SBA-1-alk materials synthesized with diluted solution $\left(1328-1432 \mathrm{~m}^{2} / \mathrm{g}\right.$ and $0.89-1.03 \mathrm{~cm}^{3} / \mathrm{g}$, respectively).

The condensation of silicate under alkaline condition is faster than that in conventional acidic condition. The condensation is considered to proceed even faster when more concentrated silicate solution is used. The more rapid condensation should have less interference on the spherical micelles of CTEA, and lead to the formation of cubic mesoporous silica of less defects. However, the rapid condensation also leads to SBA-1-alk silica in the form of nanoparticles, which is less thermally stable and of lower surface area and pore volume. Therefore, the optimal molar composition of the reaction mixture to prepare thermally stable cubic $\mathrm{Pm} 3 \mathrm{n}$ mesoporous silica is $\mathrm{Na}_{2} \mathrm{SiO}_{3} / \mathrm{CTEABr} / \mathrm{NaCl} / \mathrm{HCl} / \mathrm{H}_{2} \mathrm{O}=1.0 / 0.26 / 6$ / $0.58 / 500$.

\subsection{Temperature effect and hydrothermal stability}

In conventional SBA-1 synthesis, the cubic phase of well-ordered pores has to be prepared near $0{ }^{\circ} \mathrm{C}$. However, through the alkaline route the cubic $P m 3 n$ mesostructure could be prepared at a temperature up to $50{ }^{\circ} \mathrm{C}$. Fig. 7A and B shows that XRD patterns corresponding to well-ordered cubic structure was observed on the as-made and water-washed samples prepared in $0-50{ }^{\circ} \mathrm{C}$. Moreover, the hydrothermal stability of the calcined samples was tested by suspending $0.5 \mathrm{~g}$ portion of the powder samples in $50 \mathrm{~mL}$ water and heated at $100^{\circ} \mathrm{C}$ in an autoclave for 5 days. Fig. 7C shows that cubic Pm3n mesostructure is retained for all samples after hydrothermal treatment. However, the one synthesized at $30^{\circ} \mathrm{C}$ shows better ordering of the mesostructure than those synthesized at 0 and $50^{\circ} \mathrm{C}$. Therefore, $30^{\circ} \mathrm{C}$ is the optimal temperature for alkaline synthesis of cubic Pm $3 n$ mesoporous silica. Table 2 shows that the surface area and porosity of the calcined and hydrothermally treated samples were still high. The pore diameter, surface area and pore volume of the sample synthesized at $30{ }^{\circ} \mathrm{C}$ were $2.3 \mathrm{~nm}, 1042 \mathrm{~m}^{2} / \mathrm{g}$ and $0.92 \mathrm{~cm}^{3} / \mathrm{g}$, respectively, and these values decreased only about $10 \%$ after the material was heated in boiling water for 5 days. In contrast, the mesostructure of SBA-1 synthesized in conventional acidic condi-
(A)

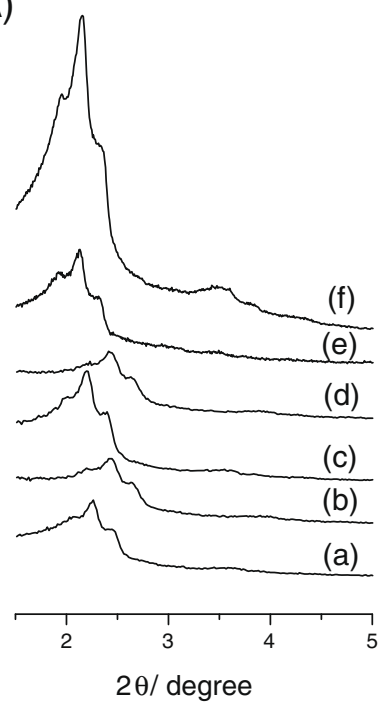

(C)

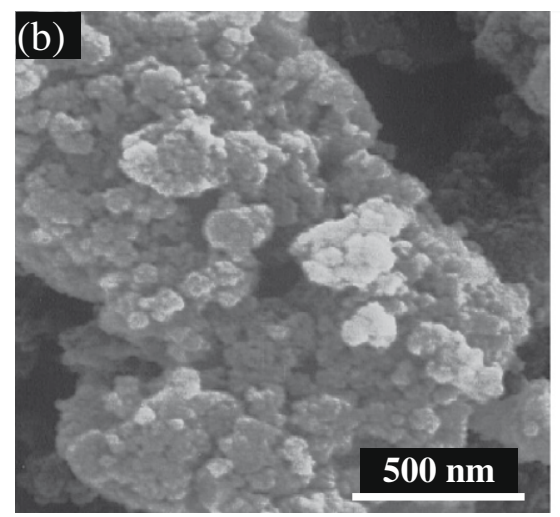

(B)
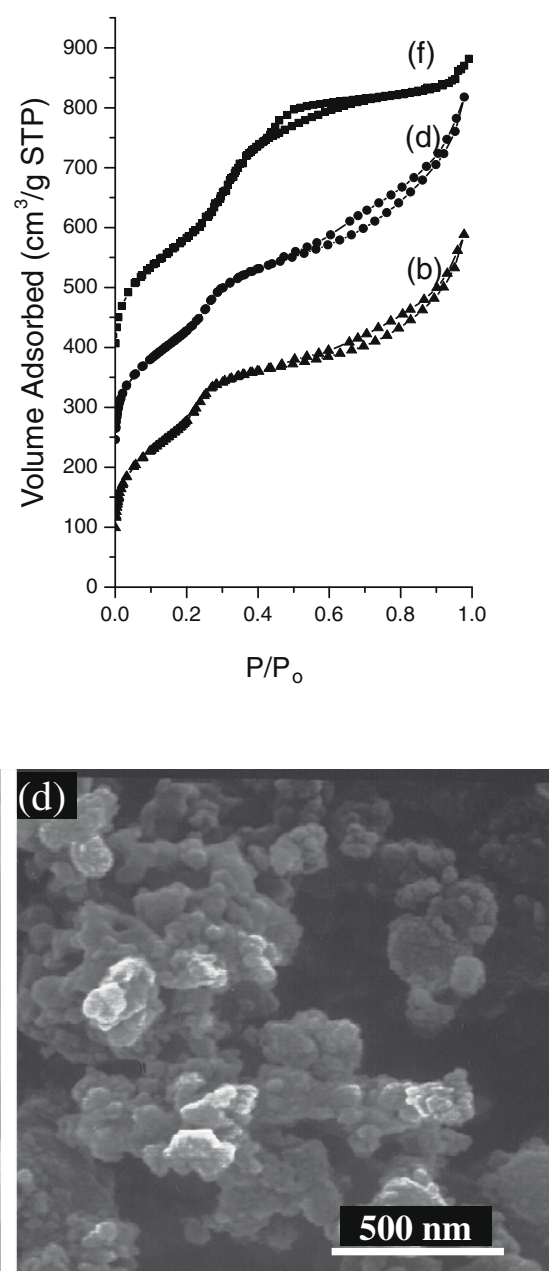

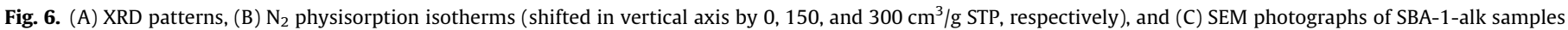

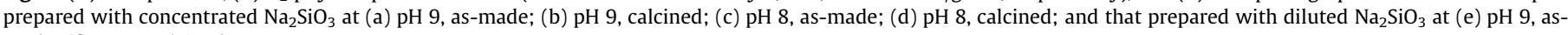
made; (f) $\mathrm{pH} \mathrm{9,} \mathrm{calcined.}$ 
(A)

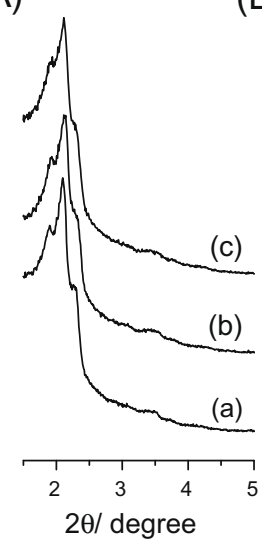

(B)

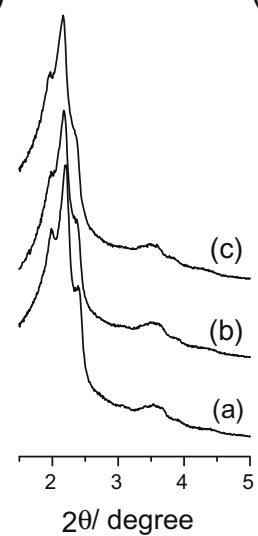

(C)

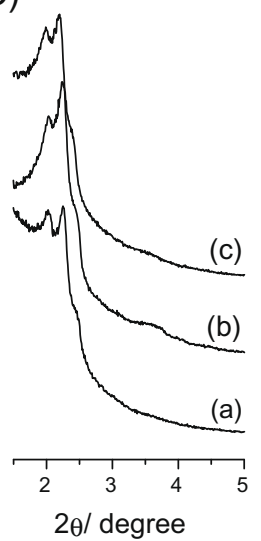

Fig. 7. XRD patterns of samples synthesized at $\mathrm{pH} 9$ and aging temperature of (a) $0{ }^{\circ} \mathrm{C}$, (b) $30^{\circ} \mathrm{C}$, (c) $50{ }^{\circ} \mathrm{C}$ : (A) water-washed, (B) calcined, and (C) calcined and hydrothermally treated at $100{ }^{\circ} \mathrm{C}$ for 5 days. The molar composition is $\mathrm{Na}_{2} \mathrm{SiO}_{3} /$ $\mathrm{CTEABr} / \mathrm{NaCl} / \mathrm{HCl} / \mathrm{H}_{2} \mathrm{O}=1.0 / 0.26 / 6.0 / 0.58 / 500$

tion collapsed just by washing with water at room temperature [15].

\subsection{Comparisons of cubic Pm3n mesoporous silica synthesized in alkaline and acidic conditions}

The formation rates of cubic Pm3n mesophase under acidic and alkaline conditions were compared by carrying out in situ XRD

Table 2

Structural parameters of calcined SBA-1-alk samples synthesized at $\mathrm{pH} 9$ and different temperatures after hydrothermal treatment.

\begin{tabular}{llll}
\hline$T\left({ }^{\circ} \mathrm{C}\right)$ & $S_{\text {BET }}\left(\mathrm{m}^{2} / \mathrm{g}\right)$ & $D_{\text {meso }}(\mathrm{nm})$ & $V_{\text {pore }}\left(\mathrm{cm}^{3} / \mathrm{g}\right)$ \\
\hline 0 & $1432(911)$ & $2.5(2.3)$ & $1.03(0.88)$ \\
30 & $1174(1042)$ & $2.6(2.3)$ & $1.05(0.92)$ \\
50 & $1098(979)$ & $2.6(2.3)$ & $1.02(0.91)$
\end{tabular}

* $0.5 \mathrm{~g}$ of calcined samples were suspended in $50 \mathrm{~mL}$ water and heated at $100{ }^{\circ} \mathrm{C}$ in the autoclave for 5 days. experiments. Fig. 8 shows that it took more than half an hour for the weak peaks corresponding to cubic $P m 3 n$ phase to be resolvable under acidic condition [13]. In contrast, well-resolved peaks of cubic Pm $3 n$ phase were observed in several minutes after adding sodium silicate into the surfactant solution when preparing the material at $\mathrm{pH}$ 9. These results demonstrate that the silicate condensation is much faster in alkaline condition than in the acid.

TGA studies compared the thermal decomposition of $\mathrm{CTEA}^{+}$ template in cubic Pm3n silica prepared by the acidic and alkaline routes. Fig. 9 shows that the water-washed SBA-1-alk prepared at pH 9 has a weight loss of $44 \%$ at $223{ }^{\circ} \mathrm{C}$, while the SBA- 1 prepared at $\mathrm{pH}-0.1$ has a slightly larger weight loss of $48 \%$ at a higher temperature of $255^{\circ} \mathrm{C}$. These results are in consistence with those observed for CTMA-containing mesoporous materials prepared in acidic and basic conditions [36]. The CTMA template in MCM-41 which was synthesized in basic condition decomposed at lower temperatures than that in SBA-3 which was a product of acidic synthesis. Kleitz et al. [36] proposed that the strong basicity of $\mathrm{Si}-\mathrm{O}^{-}$groups would promote the Hofmann elimination of the CTMA template. The mesoporous silica synthesized in alkaline condition contains silanol groups mainly in the deprotonated $\mathrm{Si}-\mathrm{O}^{-}$ form on the surface, while those synthesized in acids are in the form of $\mathrm{Si}-\mathrm{OH}$ or $\mathrm{Si}-\mathrm{OH}_{2}^{+}$. Similar decomposition mechanism can account for the lower decomposition temperature of $\mathrm{CTEA}^{+}$template in SBA-1-alk synthesized in alkaline condition than that in SBA-1 synthesized in acids.

The small amount of hydrochloric acid present in the surfactant solution before the addition of sodium silicate was found essential for the preparation of cubic Pm3n mesoporous silica, although the acid was neutralized by sodium silicate latter and the final $\mathrm{pH}$ of the solutions was varied in 3-11. It should be noticed that the amount of acid used $\left(\mathrm{HCl} / \mathrm{Na}_{2} \mathrm{SiO}_{3} \sim 0.56-0.83\right)$ is much lower than that in the conventional acidic synthesis route $(\mathrm{HCl} / \mathrm{TEOS} \sim 3-140)$ $[11,12,15,17-20]$. On the other hand, if the same amount of nitric acid instead of $\mathrm{HCl}$ was used, two-dimensional-hexagonal mesoporous silica was obtained (Fig. 10). The formation of mesostructured silica of different phases in different acids using CTEA ${ }^{+}$ surfactant under strong acidic conditions has been reported in the literature [37]. These results infer that the structures of the $\mathrm{CTEA}^{+}$micelles are strongly influenced by the acids used. The globular micelles, which served as the template for the cubic mesostructure and formed in the acidic environment, are stabilized by
(A)

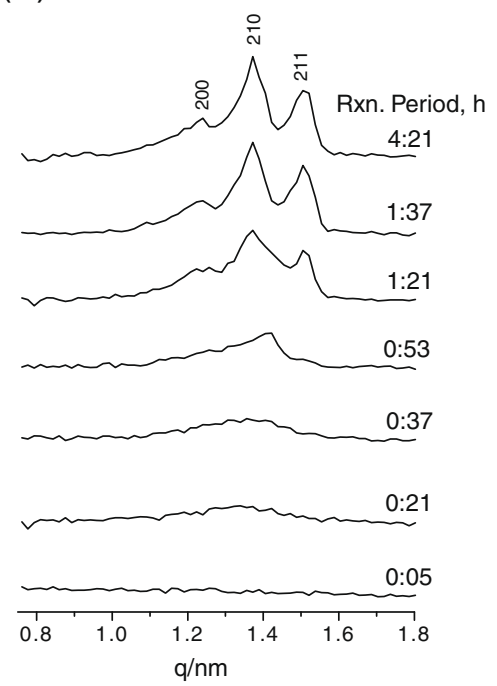

(B)

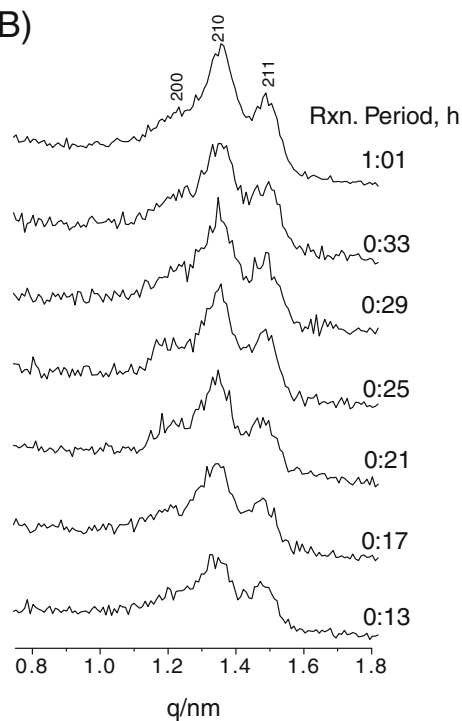

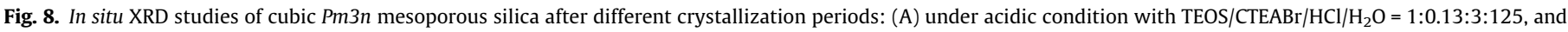
(B) under alkaline condition at $\mathrm{pH} 9$ with $\mathrm{Na}_{2} \mathrm{SiO}_{3} / \mathrm{CTEABr} / \mathrm{NaCl} / \mathrm{HCl} / \mathrm{H}_{2} \mathrm{O}=1.0 / 0.26 / 6.0 / 0.58 / 500$. 
(A)

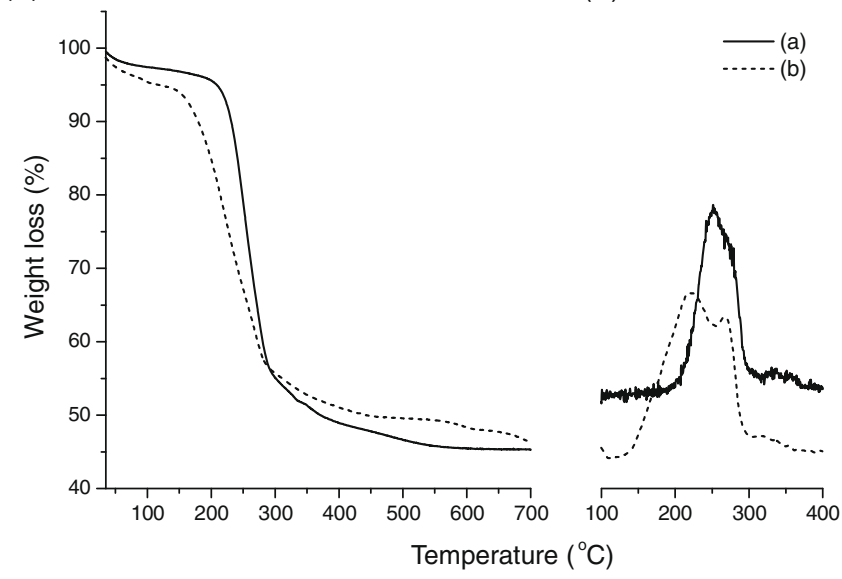

Fig. 9. (A) TGA and (B) DTG profiles taken in air atmosphere of as-made cubic $P m 3 n$ mesoporous silica prepared at $\mathrm{pH}$ value of (a) -0.1 and (b) 9 .

the chloride anions. If nitric acid is used instead of $\mathrm{HCl}$, cylindrical micelles of $\mathrm{CTEA}^{+}$are formed and stabilized by nitrate anions. In the alkaline synthesis route, the small amount of acids added in the surfactant solutions is apparently enough to determine the structure of the micelles. The sodium silicate added later should

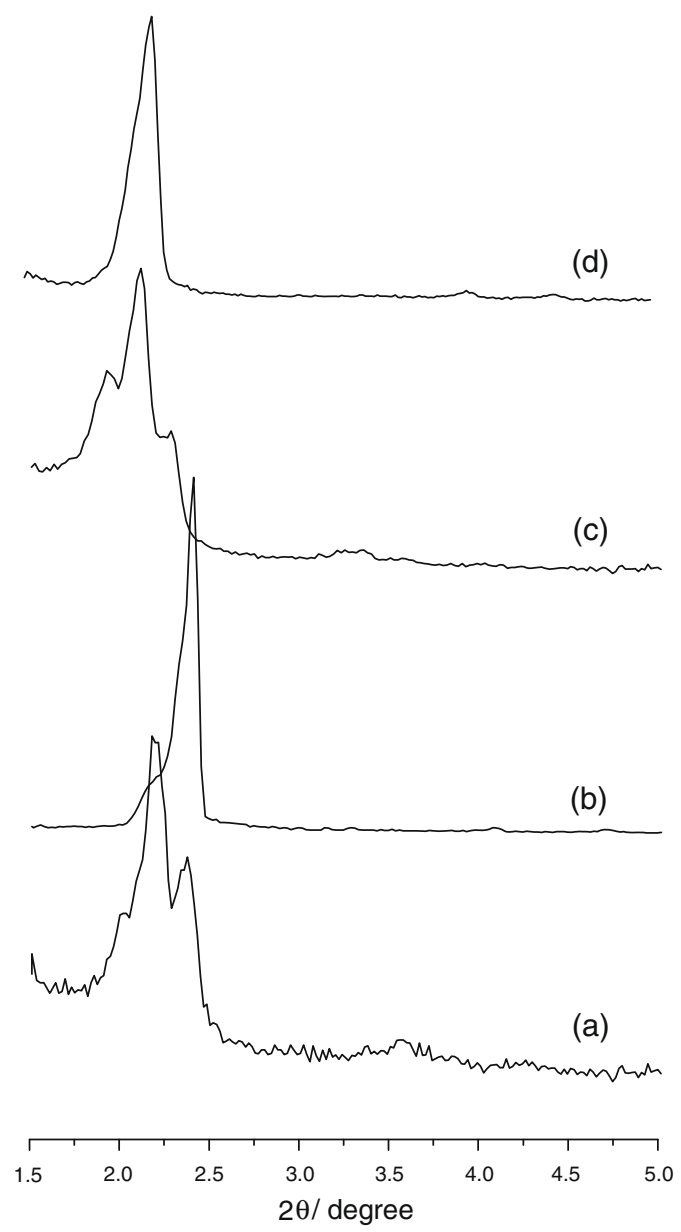

Fig. 10. XRD patterns of mesoporous materials prepared using $\mathrm{CTEA}^{+}$surfactant and (a) under strong acidic condition with $\mathrm{HCl}$, (b) under strong acidic condition with $\mathrm{HNO}_{3}$, (c) at pH 9 started with a small amount of $\mathrm{HCl}$, and (d) at pH 9 started with a small amount of $\mathrm{HNO}_{3}$. condensate around the micelles in such a rapid rate that the micelle structure is retained.

\subsection{Pyrene fluorescence studies}

The micelle environment in the mesoporous silica was studied by pyrene fluorescence techniques. Trace amount of pyrene $(3 \mu \mathrm{M})$ was dissolved in $\mathrm{CTEA}^{+}$micelles $(0.058 \mathrm{M})$ before the introduction of the silica source. The pyrene fluorescence fine structure shows five predominant peaks in UV-Vis region [38,39]. The typical pyrene spectra of mesoporous silica prepared using $\mathrm{CTEA}^{+}$surfactant are shown in Fig. 11A. The $0-0$ vibronic transition from the ground state to the lowest excited electronic state gives rise to the so-called emission peak 1 ( $I_{1}$ peak) at $374 \mathrm{~nm}$, which is symmetryforbidden. Its intensity is increased by the distortion of the $\pi$-electron cloud in polar media, while the emission peak 3 ( $I_{3}$ peak) at $385 \mathrm{~nm}$ is symmetry-allowed and solvent-insensitive. Usually, the $I_{3}$ peak shows minimal intensity variation with polarity, whereas $I_{1}$ peak shows significant intensity enhancement in polar solvents. As a result, the $I_{1} / I_{3}$ ratio is larger when the micro-environment of pyrene is more polar [37]. The $I_{1} / I_{3}$ ratio is 1.7 in water, and 0.58 in cyclohexane [40].

The $I_{1} / I_{3}$ intensity ratios obtained on the mesophase silica synthesized using pyrene-containing $\mathrm{CTEA}^{+}$micelles with either $\mathrm{HCl}$ or $\mathrm{HNO}_{3}$ as the acid source are compared in Table 3. To avoid the interference from salt effect under alkaline synthesis condition, $\mathrm{NaCl}$ was the salt when $\mathrm{HCl}$ was the acid and $\mathrm{NaNO}_{3}$ was the salt when $\mathrm{HNO}_{3}$ was the acid. The mesophases obtained with $\mathrm{HCl}$ and $\mathrm{HNO}_{3}$ were cubic Pm3n and two-dimensional-hexagonal, respectively, and that is not affected by either acidic or alkaline synthesis route, as shown in Fig. 10 . The $I_{1} / I_{3}$ intensity ratios were in 1.51-1.54 for mesostructured silica synthesized by conventional acidic route with $\mathrm{HCl}$ or $\mathrm{HNO}_{3}$ as the acid source, and that decreased to $1.36-1.40$ for the materials synthesized by the alkaline route. These values imply that although pyrene is considered a hydrophobic molecule and dissolved in the hydrophobic part of the micelle, it is probably situated in a short distance from the hydrophilic head-groups of the $\mathrm{CTEA}^{+}$micelle instead of at the center of the hydrophobic core. Moreover, the $I_{1} / I_{3}$ ratios for the silica synthesized in acids are close to the value (1.54) for pyrene-containing micelles of $\mathrm{CTEABr}$ in aqueous solution. That implies that the micro-environment of the micelles in the silica prepared by acidic route is similar to that in aqueous solution. In other words, there should be a large amount of water around the micelles in the mesopores. These results are consistent with the mechanism proposed by Egger et al. [41] that a drastic change in the water activity in the interface between micelle and silica is responsible for the conventional SBA-1 mesophase formation. Comparatively, the lower $I_{1} / I_{3}$ ratios for mesostructured silica synthesized under alkaline condition imply that pyrene is seated in a relatively hydrophobic environment or less amount of water is present in the interface between micelle and silica framework.

The pyrene fluorescence lifetime was utilized to probe the species near the micelle (Fig. 11B). For the mesostructured silica synthesized by acidic route, the lifetimes were 223 and 70 ns with $\mathrm{HCl}$ and $\mathrm{HNO}_{3}$ as the acid sources, respectively. The variation of lifetime with different acids confirms that the cationic micelles and protonated silica are assembled through an $\mathrm{S}^{+} \mathrm{X}^{-} \mathrm{I}^{+}$type interaction, where $\mathrm{X}^{-}$is the counter-anion of the acids. The shorter lifetime observed in $\mathrm{HNO}_{3}$ than in $\mathrm{HCl}$ implies that the $\mathrm{NO}_{3}^{-}$ion is more powerful than $\mathrm{Cl}^{-}$in quenching pyrene fluorescence. On the other hand, the fluorescence lifetimes for mesostructured silica synthesized in alkaline condition with the aid of $\mathrm{NaCl}$ and $\mathrm{NaNO}_{3}$ salts were nearly independent of the counter-anions of the acids or salts. The values were in a close range of 236 and 202 ns with $\mathrm{HCl}$ and $\mathrm{HNO}_{3}$ as the acid sources, respectively. These results sug- 

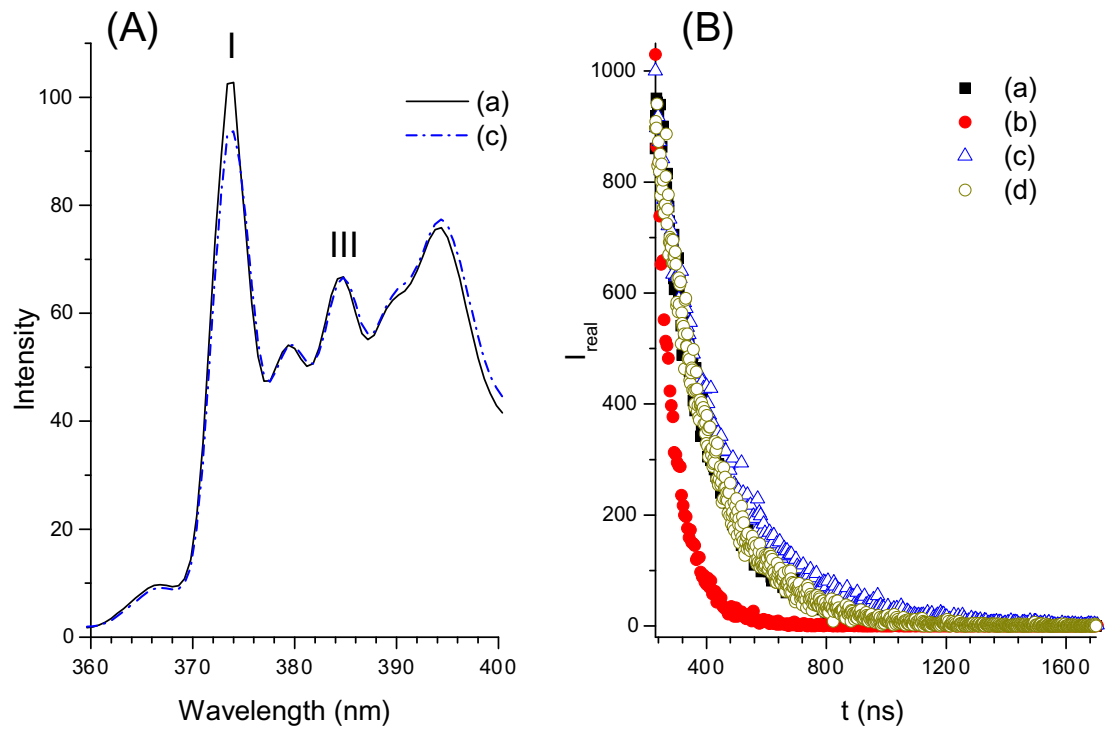

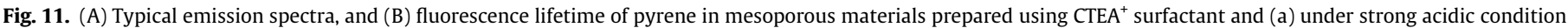
with $\mathrm{HCl}$, (b) under strong acidic condition with $\mathrm{HNO}_{3}$, (c) at $\mathrm{pH} 9$ started with a small amount of $\mathrm{HCl}$, and (d) at $\mathrm{pH} 9$ started with a small amount of $\mathrm{HNO}_{3}$.

gest that little amounts of the counter-anions are incorporated in the interface, and the cationic micelle and silica are assembled through an $\mathrm{S}^{+} \mathrm{I}^{-}$type interaction.

The direct ion-pairing mechanism between the surfactant and silicate, and the more hydrophobic environment shown by pyrene fluorescence all direct for more compact replication of the micelles under alkaline conditions. Table 1 compares the unit cell parameters of the SBA-1-alk synthesized in alkaline conditions with that of conventional SBA-1 (synthesized at $\mathrm{pH}-0.3$, TEOS $/ \mathrm{CTEABr} / \mathrm{HCl} /$ $\left.\mathrm{H}_{2} \mathrm{O}=1.0 / 0.13 / 5.0 / 125\right)$. For the as-made samples prepared under alkaline conditions, the $\mathrm{a}_{0}$ values are indeed smaller than that made in acid. After calcination, however, the unit cell shrank more markedly for the sample prepared in acid (from 9.58 to $8.63 \mathrm{~nm}$ ) than those prepared in alkaline conditions. The more intense shrinkage of the sample prepared in acid can be elucidated by the less complete condensation of the silica framework, which is confirmed by the ${ }^{29} \mathrm{Si}$ MAS NMR spectra of the as-made samples shown in Fig. 3. As a result, the pore diameters of calcined SBA1-alk materials synthesized under alkaline conditions are larger than that of conventional SBA-1.

\subsection{Al-incorporated cubic Pm3n mesoporous silica}

In order to demonstrate that hetero-elements could be efficiently incorporated into the framework of cubic Pm3n mesoporous silica by the alkaline synthetic route, sodium aluminate were mixed into the sodium silicate before introduction of CTEABr tem-

Table 3

The fluorescence intensity $I_{1} / I_{3}$ ratios and lifetimes $(\tau)$ of pyrene in the mesoporous silica synthesized by different routes.

\begin{tabular}{|c|c|c|c|c|}
\hline \multirow[t]{3}{*}{ Acid source } & \multicolumn{4}{|c|}{ Synthesis route } \\
\hline & \multicolumn{2}{|c|}{ Acidic $^{a}$} & \multicolumn{2}{|c|}{ Alkaline $^{\mathrm{b}}$} \\
\hline & $I_{1} / I_{3}$ & $\tau(\mathrm{ns})$ & $I_{1} / I_{3}$ & $\tau(\mathrm{ns})$ \\
\hline $\mathrm{HCl}$ & 1.54 & 223 & 1.40 & 236 \\
\hline $\mathrm{HNO}_{3}$ & 1.51 & 70 & 1.36 & 220 \\
\hline
\end{tabular}

${ }^{a}$ Mesoporous silica was prepared following the procedures in Ref. [34]. The molar composition of the synthesis gel was TEOS/CTEABr/acid $/ \mathrm{H}_{2} \mathrm{O}=1: 0.13: 3: 125$

b Salts were $\mathrm{NaCl}$ and $\mathrm{NaNO}_{3}$ for $\mathrm{HCl}$ and $\mathrm{HNO}_{3}$ acids, respectively, at final $\mathrm{pH}$ of 9 . plate in the synthesis procedure and the final $\mathrm{pH}$ of the synthesis solution was adjusted to around 9. The XRD patterns confirmed that the resultant materials retained cubic $\operatorname{Pm} 3 n$ phase although the diffraction peaks became broader with the increase in $\mathrm{Al}(\mathrm{III})$ loading (Fig. 12A). The results of elemental analysis and the physical properties determined by $\mathrm{N}_{2}$ sorption on the calcined samples are given in Table 4. The amounts of $\mathrm{Al}(\mathrm{III})$ ions incorporated in the solids are close to those in the synthesis solutions up to $\mathrm{Al} / \mathrm{Si}$ atomic ratio of $5 \%$. With the $\mathrm{Al} / \mathrm{Si}$ atomic ratios in $1-5 \%$, the BET surface area and pore volume of the samples retain high $\left(990-1243 \mathrm{~m}^{2} / \mathrm{g}\right.$ and $0.89-0.90 \mathrm{~cm}^{3} / \mathrm{g}$, respectively). Above $5 \%$, the incorporation efficiency of $\mathrm{Al}(\mathrm{III})$ and the pore volume of the resultant material decrease rapidly. ${ }^{27} \mathrm{Al}$ solid state MAS NMR spectra of the calcined samples containing $\mathrm{Al} / \mathrm{Si}$ in $1-5 \%$ show only a single peak at $50 \mathrm{ppm}$ assigned to the tetrahedrally coordinated aluminum (Fig. 12). The absence of signals around $0 \mathrm{ppm}$, corresponding to the octahedrally coordinated aluminum, indicates that no extraframework alumina species were formed. For cubic Pm3n mesoporous silica prepared with $\mathrm{Al} / \mathrm{Si}=7 \%$, a small peak appears at
(A)

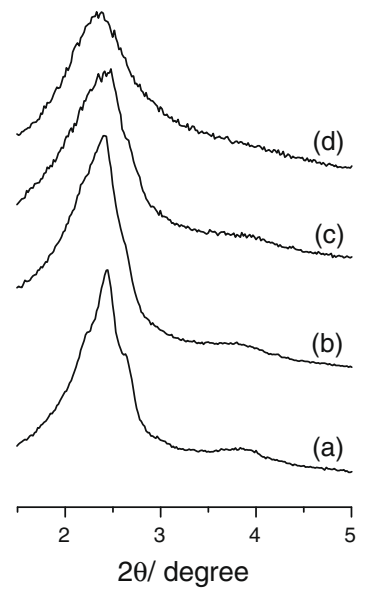

(B)

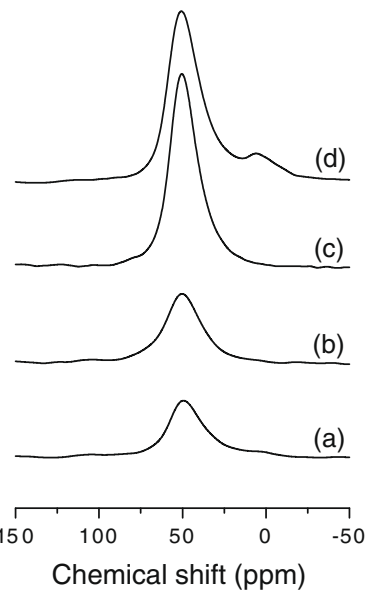

Fig. 12. (A) XRD patterns and (B) solid state ${ }^{27} \mathrm{Al}$ MAS NMR spectra of calcined AlSBA-1-alk synthesized with Al/Si molar ratio of (a) $1 \%$, (b) $2 \%$, (c) $5 \%$, and (d) $7 \%$ by the alkaline route. 
Table 4

Physico-chemical properties of the calcined siliceous and Al-substituted cubic Pm3n mesoporous silica synthesized under alkaline condition. ${ }^{\mathrm{a}}$

\begin{tabular}{|c|c|c|c|c|c|}
\hline \multirow[t]{2}{*}{ Samples } & \multirow[t]{2}{*}{$S_{\mathrm{BET}}\left(\mathrm{m}^{2} / \mathrm{g}\right)$} & \multirow[t]{2}{*}{$V_{\text {pore }}{ }^{\mathrm{b}}\left(\mathrm{cm}^{3} / \mathrm{g}\right)$} & \multirow[t]{2}{*}{$D_{\text {pore }}(\mathrm{nm})$} & \multicolumn{2}{|c|}{$\underline{\mathrm{Al} / \mathrm{Si} \text { atomic ratio }}$} \\
\hline & & & & Solution & Solid $^{\mathrm{c}}$ \\
\hline SBA-1-alk & 1432 & 1.03 & 2.5 & - & - \\
\hline 1\% Al-SBA-1-alk & 1243 & 0.90 & 2.5 & 0.01 & 0.013 \\
\hline $2 \%$ Al-SBA-1-alk & 1004 & 0.90 & 2.4 & 0.02 & 0.020 \\
\hline $5 \%$ Al-SBA-1-alk & 990 & 0.89 & 2.4 & 0.05 & 0.045 \\
\hline 7\% Al-SBA-1-alk & 984 & 0.68 & 2.3 & 0.07 & 0.049 \\
\hline
\end{tabular}

a $\mathrm{pH} 9$ with $\mathrm{Na}_{2} \mathrm{SiO}_{3} / \mathrm{NaAlO}_{2} / \mathrm{CTEABr} / \mathrm{NaCl} / \mathrm{HCl} / \mathrm{H}_{2} \mathrm{O}=1.0 / 0.01-0.07 / 0.26 / 6 / 0.60 / 500$.

b The pore volume was accumulated until $P / P_{0}=0.95$.

c Analyzed by ICP-MS.

$0 \mathrm{ppm}$ on the ${ }^{27} \mathrm{Al}$ solid state MAS NMR spectrum, indicating that a small portion of $\mathrm{Al}(\mathrm{III})$ ions forms extra-framework alumina species. Therefore, the $\mathrm{Al}(\mathrm{III})$ ions are efficiently incorporated into the silica framework of cubic Pm3n mesostructure through the alkaline synthesis route up to $\mathrm{Al} / \mathrm{Si}=5 \%$.

\subsection{Catalytic properties of Al-incorporated cubic Pm3n mesoporous} silica

The alkylation of 2,4-di-tert-butylphenol (DTBP) by cinnamyl alcohol and the subsequent isomerization of primary cinnamyphenol intermediate to yield flavan in the liquid phase was chosen as a model reaction to evaluate the catalytic activities of Al-containing cubic Pm $3 n$ mesoporous silica. Table 5 compares the catalytic activities of Al-SBA-1-alk with those of H-ZSM-5 and HY zeolites. The reactant 2,4-DTBP is too large to enter the pores of ZSM-5. Hence, the reaction should proceed only on the outer surfaces of ZSM-5 particles. Although the reaction was suggested to be catalyzed by moderately acidic sites [24,25], ZSM-5 gave higher 2,4-
DTBP conversion and much higher turnover numbers (TON) than HY. It is attributed to the stronger acidic strength on ZSM-5. Moreover, the very low TON over HY zeolite implies that the reaction should proceed merely on the outer surface of HY. In spite of having larger pore dimensions, the acidity of Al-substituted mesoporous materials like Al-MCM-41, is considered to be much weaker than that of microporous zeolites [42]. Nevertheless, the 2,4-DTBP conversion and flavan yield increase with Al-loading in Al-SBA-1alk catalysts up to $\mathrm{Al} / \mathrm{Si}=5 \%$. The conversion decreases slightly when the $\mathrm{Al} / \mathrm{Si}$ ratio is $7 \%$, which is attributed to the lower pore volume and a portion of the Al forming extra-framework alumina. The flavan selectivities are similar to that over HY zeolite, and that is the thermodynamic equilibrium distribution between cinnamylphenol and flavan [43]. The lower flavan selectivity over ZSM-5 is probably due to that the ring closure reaction of cinnamylphenol is restricted by the relatively low amount of acid sites on the outer surfaces of ZSM-5. On the other hand, the 2,4-DTBP conversion and flavan yield over Al-SBA-1-alk with $\mathrm{Al} / \mathrm{Si}$ ratios of $2-5 \%$ are higher than those over H-ZSM-5 and HY zeolites, although both

Table 5

Alkylation of 2,4-di-tert-butylphenol with cinnamyl alcohol over Al-SBA-1-alk with different Al-loadings. ${ }^{a}$<smiles>CC(C)(C)c1cc(CC=Cc2ccccc2)c(O)c(C(C)(C)C)c1</smiles>
(DTBP)<smiles>CC(C)(C)c1cc2c(c(C(C)(C)C)c1)OC(c1ccccc1)CC2</smiles>

\begin{tabular}{|c|c|c|c|c|c|c|}
\hline \multirow[t]{2}{*}{ Catalyst } & \multicolumn{2}{|c|}{$\mathrm{Al} / \mathrm{Si}$ atomic ratio } & \multirow{2}{*}{$\begin{array}{l}\text { 2,4-DTBP } \\
\text { Conv. (\%) }\end{array}$} & \multicolumn{3}{|l|}{ Flavan } \\
\hline & EDX & ICP-MS & & Yield (\%) & Select. (\%) & $\operatorname{TON}\left(\mathrm{h}^{-1}\right)$ \\
\hline SBA-1-alk & - & - & 0 & 0 & 0 & 0 \\
\hline $1 \%$ Al-SBA-1-alk & 0.009 & 0.013 & 7.2 & 6.2 & 86.3 & 0.030 \\
\hline $2 \%$ Al-SBA-1-alk & 0.015 & 0.020 & 11.3 & 9.8 & 86.5 & 0.031 \\
\hline $5 \%$ Al-SBA-1-alk & 0.038 & 0.045 & 14.5 & 12.6 & 87.2 & 0.018 \\
\hline $7 \%$ Al-SBA-1-alk & 0.045 & 0.049 & 13.7 & 11.9 & 86.9 & 0.015 \\
\hline H-ZSM- $5^{b}$ & 0.02 & - & 9.7 & 7.7 & 79.2 & 0.024 \\
\hline $\mathrm{HY}^{\mathrm{c}}$ & 0.25 & - & 5.3 & 4.6 & 86.8 & 0.0011 \\
\hline
\end{tabular}

${ }^{\mathrm{a}}$ Reaction conditions: catalyst $(100 \mathrm{mg}), 2,4-\mathrm{DTBP}(0.25 \mathrm{mmol})$, cinnamyl alcohol $(0.20 \mathrm{mmol}), \mathrm{DMSO}(12.5 \mathrm{~mL}), 95{ }^{\circ} \mathrm{C}, 24 \mathrm{~h}$.

b H-ZSM-5: pore size $0.53 \mathrm{~nm}$.

c HY zeolite: pore size $0.74 \mathrm{~nm}$. 
zeolites have higher $\mathrm{Al}$ contents. These results indicate that the acidities generated on Al-incorporated cubic Pm $3 n$ mesoporous silica are efficient to catalyze alkylation of 2,4-di-tert-butylphenol by cinnamyl alcohol to yield flavan. Furthermore, the highest TON was obtained over the two Al-SBA-1-alk catalysts with the lowest $\mathrm{Al}$ contents, inferring that the large mesopores of cubic Pm $3 n$ mesoporous silica should facilitate the bulky reactant and intermediate molecules to diffuse and access the acidic sites inside the pores. However, as the Al-loading is further increased, the surface area decreases and a portion of aluminum may be buried inside the silica framework and not accessible. As a result, the TON decreases with the increase in Al-loading on SBA-1-alk.

\section{Conclusions}

The cubic mesoporous silica of $P m 3 n$ phase was successfully synthesized under a wide $\mathrm{pH}$ range of 3-11 using CTEABr as template, sodium silicate as silica source with the aid of $\mathrm{NaCl}$ salt. The resultant materials characterized by X-ray powder diffraction, nitrogen adsorption, and ${ }^{29} \mathrm{Si}$ MAS NMR showed that the optimal synthesis condition in order to obtain the highest surface area and pore volume was at $\mathrm{pH} 9$ and with a $\mathrm{NaCl} / \mathrm{Si}$ molar ratio of 6 . The hydrothermal stability of the mesoporous materials was further improved by raising the aging temperature from conventional 0 to $30{ }^{\circ} \mathrm{C}$. The pore diameter, surface area and pore volume of the cubic Pm $3 n$ mesoporous silica synthesized at $30^{\circ} \mathrm{C}$ decreased only about $10 \%$ after the material was heated in boiling water for 5 days. Moreover, pyrene fluorescence technique was utilized to probe the micelle environment in the mesoporous silica. Instead of the weak electrostatic interaction of $\mathrm{S}^{+} \mathrm{X}^{-} \mathrm{I}^{+}$type proposed for the self-assembly of the surfactant and silicate in acids, the chemical forces governed the self-assembly under alkaline condition were $\mathrm{S}^{+} \mathrm{I}^{-}$type interaction. Through the alkaline route, the direct metal incorporation into the framework of cubic $P m 3 n$ mesoporous silica was found very efficient. Probed by ${ }^{27} \mathrm{Al}$ MAS NMR, $\mathrm{Al}(\mathrm{III})$ ions could isomorphously substitute $\mathrm{Si}$ at the tetrahedral sites of the silica framework up to a $\mathrm{Al} / \mathrm{Si}$ atomic ratio of $5 \%$. Moreover, the Al-incorporated cubic Pm $3 n$ mesoporous silica materials were found to be efficient catalysts for the alkylation of 2,4-di-tert-butylphenol by cinnamyl alcohol to yield flavan. The alkaline synthesis route developed in the present study expands the applications of cubic $P m 3 n$ mesoporous silica in sorption and catalytic reactions.

\section{Acknowledgments}

Financial supports from Ministry of Education and National Science Council of Taiwan are gratefully acknowledged. Acknowledgments are also extended to C.-Y. Tang, C.-Y. Lin, and C.-S. Kao of Instrumentation Center, National Taiwan University for EM and TA analysis experiments, and C.-N. Ke of National Tsing-Hua University for the ICP-AES experiments. We also thank Profs. P.-T.
Chou and J.-S. Yang of Department of Chemistry, NTU for the assistance in fluorescence measurement.

\section{References}

[1] C.T. Kresge, M.E. Leonowicz, W.J. Roth, J.C. Vartuli, J.S. Beck, Nature 359 (1992) 710.

[2] .A. Monnier, F. Schuth, Q. Huo, D. Kumar, D. Margolese, R.S. Maxwell, G.D. Stucky, M. Krishnamurty, P. Petroff, A. Firouzi, M. Janicke, B.F. Chmelka, Science 261 (1993) 1299.

[3] Q.S. Huo, D.I. Margolese, U. Ciesla, P.Y. Feng, T.E. Gier, P. Sieger, R. Leon, P.M. Petroff, F. Schüth, G.D. Stucky, Nature 368 (1994) 317.

[4] Q. Huo, D.I. Margolese, G.D. Stucky, Chem. Mater. 8 (1996) 1147.

[5] X. Wang, C.-C. Chen, S.-Y. Chen, Y. Mou, S. Cheng, Appl. Catal. 281 (2005) 47.

[6] D. Das, J.-F. Lee, S. Cheng, J. Catal. 223 (2004) 152.

[7] J.M. Thomas, R. Raja, J. Organomet. Chem. 689 (2004) 4110.

[8] B. Yuliarto, H.S. Zhou, T. Yamada, I. Honma, Y. Katsumura, M. Ichihara, Anal. Chem. 76 (2004) 6719.

[9] P. Yang, T. Deng, D. Zhao, P. Feng, D. Pine, B.F. Chmelka, G.M. Whitesides, G.D. Stucky, Science 282 (1998) 2244

[10] V.S.-Y. Lin, C.-Y. Lai, J. Huang, S.-A. Song, S. Xu, J. Am. Chem. Soc. 123 (2001) 11510.

[11] Q. Huo, D.I. Margolese, U. Ciesla, D.G. Demuth, P. Feng, T.E. Gier, P. Sieger, A. Firouzi, B.F. Chmelka, F. Schuth, G.D. Stucky, Chem. Mater. 6 (1994) 1176.

[12] M. Kim, R. Ryoo, Chem. Mater. 11 (1999) 487.

[13] M.-C. Liu, H.-S. Sheu, S. Cheng, Chem. Commun. (2002) 2854.

[14] M. Ogura, H. Miyishi, S.P. Naik, T. Okubo, J. Am. Chem. Soc. 126 (2004) 10937.

[15] A. Vinu, V. Murugesan, M. Hartmann, Chem. Mater. 15 (2003) 1385.

[16] H.-M. Kao, C.-C. Ting, A. Chiang, C.-C. Teng, C.-H. Chen, Chem. Commun. (2005) 1058 .

[17] X. Zhao, X. Wang, J. Mol. Catal. A 261 (2007) 225.

[18] D. Ji, R. Zhao, G. Lv, G. Qian, L. Yan, J. Suo, Appl. Catal. A: Gen. 281 (2005) 39.

[19] A. Vinu, T. Krithiga, V. Balasubramanian, A. Asthana, P. Srinivasu, T. Mori, K. Ariga, G. Ramanath, P.G. Ganesan, J. Phys. Chem. B 110 (2006) 11924

[20] M. Hartmann, A. Vinu, S.P. Elangovan, V. Murugesan, W. Böhlmann, Chem. Commun. (2002) 1238

[21] M.-C. Chao, D.-S. Wang, H.-P. Lin, C.-Y. Mou, J. Mater. Chem. 13 (2003) 2853.

[22] C.C. Pantazis, P.J. Pomonis, Chem. Mater. 15 (2003) 2299.

[23] Y. Sakamoto, M. Kaneda, O. Terasaki, D.Y. Zhao, J.M. Kim, G. Stucky, H.J. Shin, R. Ryo, Nature 408 (2000) 449.

[24] T.R. Pauly, Y. Liu, T.J. Pinnavaia, S.J.L. Billinge, T.P. Rieker, J. Am. Chem. Soc. 121 (1999) 8835.

[25] Q. Yang, Y. Li, L. Zhang, J. Yang, J. Liu, C. Li, J. Phys. Chem. B 108 (2004) 7934.

[26] F. Yu, J.-L. Shi, H.-R. Chen, J.-N. Yan, D.-S. Yan, Micropor. Mesopor. Mater. 46 (2001) 153.

[27] R. Ryoo, S. Jun, J. Phys. Chem. 101 (1997) 317

[28] J.M. Kim, S.K. Kim, R. Ryoo, Chem. Commun. (1998) 259.

[29] J.M. Kim, S. Jun, R. Ryoo, J. Phys. Chem. B 103 (1999) 6200.

[30] Y.Q. Wang, C.-M. Yang, B. Zibrowius, B. Spliethoff, M. Linden, F. Schuth, Chem. Mater. 15 (2003) 5029

[31] A. Karkamkar, S.S. Kim, T. Pinnavaia, J. Chem. Mater. 15 (2003) 11.

[32] S.-Y. Chen, L.-Y. Jang, S. Cheng, Chem. Mater. 16 (2004) 4174.

[33] H.-P. Lin, C.-P. Kao, C.-Y. Mou, Micropor. Mesopor. Mater. 48 (2001) 135

[34] S.-Y. Chen, S. Cheng, Chem. Mater. 19 (2007) 3041.

[35] S. Che, Y. Sakamoto, O. Terasaki, T. Tatsumi, Chem. Mater. 13 (2001) 2237.

[36] F. Kleitz, W. Schmidt, F. Schuth, Micropor. Mesopor. Mater. 65 (2003) 1.

[37] S. Che, S.H. Lim, M. Kaneda, H. Yoshitake, O. Terasaki, T. Tatsumi, J. Am. Chem. Soc. 124 (2002) 13962

[38] F. Reiss-Husson, V. Luzzati, J. Phys. Chem. 68 (1964) 3504.

[39] K. Kalyanasundaram, J.K. Thomas, J. Am. Chem. Soc. 99 (1977) 2039.

[40] D.C. Dong, M.A. Winnik, Can. J. Chem. 162 (1984) 2560.

[41] C.C. Egger, M.W. Anderson, G.J.T. Tiddy, J.L. Casci, Phys. Chem. Chem. Phys. 8 (2005) 1845.

[42] .A. Corma, V. Fornes, M.T. Navarro, J. Perez-Pariente, J. Catal. 148 (1994) 569.

[43] E. Armengol, M.L. Cano, A. Corma, H. Garcia, M.T. Navarro, Chem. Commun. (1995) 519. 